\title{
POR UMA CONCEPÇÃO DISCIPLINAR AUTÔNOMA DA INFORMAÇÃO DOCUMENTÁRIA
}

\author{
Leilah Santiago Bufrem*
}

\section{RESENHA}

MOREIRO GONZÁLEZ, José Antonio. Conceptos introductorios al estudio de la información documental. Salvador: EDUFBA/Fondo Editorial de la Pontificia Universidad Católica del Perú, 2005.

\section{INTRODUÇÃO}

Se aceito o pressuposto de que há de se manter uma linha de coerência, acadêmica ou profissional, entre a ação e os princípios que a norteiam, vale destacar a anterioridade de uma concepção disciplinar autônoma, como princípio de aprofundamento nos campos de conhecimento específicos, indissociáveis da prática. Essa concepção, por sua vez, decorre do estudo sobre o domínio científico, referência inevitável aos processos e resultados da ação concreta do intelectual. A necessária reflexão sobre o domínio da Ciência da Informação é realizada por Moreiro González, em Conceptos introductorios al estudio de la información documentária (2005). Ao contextualizar as atividades desenvolvidas pelos profissionais da informação e os conteúdos disciplinares apresentados pelos programas de cursos, o autor agrega reflexões sobre os processos técnicos por eles desenvolvidos. Essas e outras considerações trazem a tona características subsidiárias ao delineamento do contexto teórico dos conhecimentos sobre as disciplinas e atividades profissionais voltadas à informação.

Já conhecido dos brasileiros por obras e conferências, o professor Moreiro González é especialmente valorizado nas instituições e colegiados do mundo acadêmico, especialmente por uma produção constante e crítica, voltada às questões teórico-práticas da ciência da informação.

Ao informar sobre o conteúdo de sua obra, pretendo apresentá-la com enfoque em seus propósitos explícitos, iniciando pela proposta de visualizar o contexto teórico dos conhecimentos relativos ao campo dos conhecimentos documentais, origem das ramificações concretizadas em disciplinas e atividades profissionais voltadas ao objeto informação. A seguir, serão analisados os esforços por determinar o objeto de estudo da ciência da informação, assim como a função social que essa cumpre. Procurarei então acompanhar o entendimento do autor sobre traços, componentes e processos próprios dos sistemas de informação, assim como suas diversas funções. O passo seguinte, um exercício diacrônico pela história e teoria da área, relaciona-se com a cultura humana, a evolução da ciência e os fatores sociais, políticos e econômicos que compõem o seu contexto. Finalmente serão destacados os conceitos básicos da especialidade, assim como a terminologia que os define,

\footnotetext{
* Professora Titular do Departamento de Ciência e Gestão da Informação, Universidade Federal do Paraná. bufrem@milenio.com.br
} 
objetos do último capítulo da obra, fechando o caminho evolutivo e de análise conceitual que o autor delineia.

\section{SOCIEDADE DA INFORMAÇÃO E CULTURA MOSAICO}

Para construir o contexto teórico dos conhecimentos fundantes da ciência da informação, Moreiro analisa inicialmente o desenvolvimento da cidadania, proporcional ao processo de demanda por informação e complementado pela participação política. Esses elementos são geradores de um ciclo em ascensão, alimentado por um regime de produção do conhecimento, caracterizando o que Porat (1977) definiu, já há três décadas, como "economia da informação”. Nesse novo paradigma conceitual e de trabalho, analisado por Moore (1998), o conhecimento se tornou mais essencial do que o capital e a mão de obra (DRUCKER, 1993), provocando o surgimento, na década de 1960, de um profissional que viria a se destacar no cenário das profissões, o especialista em informação. Nesse contexto, denominado de "cultura mosaico", do ponto de vista sociológico (MOLES, 1983) e de "cibercultura”, do ponto de vista técnico, têm se desenvolvido modos de intervenção tecnológica a influenciar as faculdades de processamento de informação e de geração de conhecimento. Esse processo traz à luz outro vocábulo componente dessa constelação terminológica, a "era da aprendizagem”, como a destacar, segundo o autor, as extraordinárias faculdades de processamento da informação, mediante as ferramentas informáticas.

O quadro teórico de referência estaria incompleto sem a participação de Castells (2001) para contextualizar e compor o conjunto de características da sociedade da informação: o economicismo informativo; a revalorização da ecologia; uma nova ética; o mercado como política e a brecha digital. Por certo, essa última marca distintiva provoca desassossego, diante da enorme massa de informações, impossível de ser digerida e do conseqüente e perigoso pensamento único ou acrítico. Nesse contexto, a capacidade de manejar as tecnologias da informação converte-se numa forma de alfabetização: a alfabetização digital, sem a qual os cidadãos são impedidos de participar plenamente da sociedade ou adquirir os conhecimentos necessários para responder às questões do cotidiano.

Alguns traços esquemáticos delineados por Cebrián são destacados como certezas de um contexto em mudança, desde o efeito global; passando pela velocidade, não somente na transmissão de informação, mas no ritmo de crescimento e nas mudanças que produz; pela interatividade ou possibilidade intrínseca de concessão à participação ativa de quantos façam parte dos atos comunicativos; pela virtualidade, ou nova realidade; até alcançar o descontrole, pois o digital está fora dos padrões de organização precedentes.

Chegou-se a um estado em que nem informação, nem documento são estáveis e estáticos. A informação e sua manifestação expressiva, o documento, transformaram-se em realidade dinâmica, simultânea e transversal (McHALE, 1987). O fenômeno é perceptível nos documentos, segundo Pérez Tornero (2000), graças às seguintes evidências: nos conteúdos documentais interagem várias semióticas de forma sincrética e simultânea; os distintos sistemas de signos podem estabelecer relações hierárquicas entre diferentes tipos de semiótica, porém são sempre relações instáveis, variáveis e estratégicas e o sentido do 
conteúdo do documento deriva da conjunção e complementaridade de diversos tipos de signos.

Ao descrever o novo panorama, o autor destaca as cinco principais transformações na produção dos documentos. A primeira refere-se ao processo de criação e de difusão que passaram a ser digitalizados, possibilitando que documentos eletrônicos possam ser impressos, audiovisuais, sonoros e gráficos ao mesmo tempo. A segunda diz respeito à possibilidade de coincidência entre o momento da criação e o da comunicação. A multiplicidade de formas e significados das mensagens como vantagem editorial e individual é a terceira característica analisada. Como conseqüência da distribuição mais flexível do documento, a dificuldade de controlar cópias e permanência da informação desafia os defensores dos direitos autorais. E, por último, a impossibilidade de limites técnicos para a confecção de cópias do original delineia uma nova perspectiva, pela qual não se distingue entre acesso e posse, empréstimo e venda.

Nesse contexto de tão complexas características, atuam como mediadores profissionais com perfis e habilidades distintas, compondo um quadro capaz de gerar, tratar e manejar a informação com vistas ao seu usuário final.

\section{A INFORMAÇÃO: OBJETO DE ESTUDO DA CIÊNCIA DA INFORMAÇÃO}

As críticas e tentativas de superação do modelo entrópico de Shanon e Weaver (1949), para formalizar o conceito de informação, partem de sua insuficiência em dar conta do significado das mensagens. Considerando que a concepção dos autores abriu passo para uma teoria de sinais e que, portanto, não se constitui em autêntica teoria da informação, Moreiro apresenta e analisa as propostas mais representativas que se sucederam como formas de conceber a informação.

Iniciando com conceito de informação explicado pelo modelo matemático (p. 31), predominante no domínio da engenharia de sistema de comunicação, apresenta-se a possibilidade de análise a partir de unidades mensuráveis, cuja aplicação foi recorrente entre as produções da American Society for Information Science. Embora o modelo venha recebendo críticas, especialmente pelas limitações da aplicação de uma teoria de caráter mecânico a um campo complexo como o da informação/conhecimento, seu potencial para mensurar tem sido colocado em pauta, como o faz Marino (1983) ao apontar a indexação mediante cartões perfurados, utilizada por Garfield (1961) na década de 1950; a avaliação de resultados de um sistema documental, utilizando-se do ruído e da tabela de contingências e a indexação por frases, criada por Briner (1978).

O enfoque quantitativo, além disso, gerou as teorias fundamentais para a consolidação da ciência da informação, cujas teses mais antigas traduziram-se nas leis de Zipf, Bradford e Lotka. Seguiram-se Fairthone, Price, Coile, Arapov e Schereider e suas respectivas aplicações dos métodos matemáticos, tendência metodológica difusora também das atuais técnicas de recuperação e avaliação de uso da informação.

A contraproposta a partir das ciências sociais (p. 34) parte do problema básico da informação: conseguir a comunicação desejada entre emissor e usuário. O quadro de 
exigências de Belkin (1979) ilustra a informação dentro dos sistemas de comunicação cognitiva; as relações entre informação e produtor e entre informação e usuário; a idéia de informação desejada, de sua efetividade e da efetividade da sua transferência. Essa concepção abrange a noção de intencionalidade no ato de informar-se e a variação da estrutura cognitiva, incluindo, portanto, múltiplos fatores dentro de uma situação concreta, o que justifica os significados que adquire o termo informação de acordo com situações diferentes às quais se aplica.

Posteriormente, associando a mensagem prioritariamente ao sentido que ela adquire e, em menor escala, à probabilidade do emissor recebê-la, Belkin (1979) aproxima-se da teoria de Shannon e Weaver (1949), cuja ambição foi compreender a comunicação a partir de seu significado. Na mesma linha, a proposta de Belzer (1979) aplica a medida de Shannon (1951) à carga semântica contida nos textos e em suas representações. A idéia de meta-informação, tratada por Schreider (1974) para o desenvolvimento do conceito de informação semântica, sobressai, por sua vez, no estudo do modo de disposição e estrutura da informação semântica em um documento. Essa posição, integrada com os fundamentos das ciências sociais, destaca o compromisso social do profissional "informador", que transcende as tarefas de criação e organização de centros ou sistemas de informação/documentação.

O valor da informação como acesso ao conhecimento (p. 37) é um referente lançado já em 1956 por Shera, aqui analisado pelo enfoque dado à informação como atributo do conhecimento, independente da matéria em que está gravada, da energia que a transmite e do próprio signo que possibilita sua representação. Sabe-se que modifica o conhecimento, desde que o sujeito esteja preparado intelectualmente para recebê-la, ou seja, ativado por um marco cognoscitivo junto à memória deixada por anteriores situações do mesmo modelo.

Com o especial enfoque em Shera (1956), o autor recupera também o conceito de Vickery (1978) sobre o uso simultâneo de métodos tradicionais e de ponta. Utilizados a partir das necessidades do usuário, sem deixar de insistir, entretanto, no problema fundamental de reestruturação do documento em suas linhas semânticas principais, a partir da série de seus elementos representativos. A crença nos processos automáticos, consolidada a partir dos trabalhos de Luhn (SCHULTZ, 1968), aproxima a significação lingüística dos dispositivos tecnológicos, dando lugar ao modelo de Fogl (1979) para representar as teorias da origem, transferência e utilização da informação. Define-se a impossibilidade de compreender isoladamente a informação, uma vez que esta está imersa, conforme Moreiro, nos processos de conhecimento e de transformação do mundo que os homens realizam mediante sua atividade social e histórica.

Sem muita originalidade em relação à proposta de Shera (1956), a categorização de Buckland (1991) relaciona os três usos do termo informação: como objeto, ou informação documentada; como processo ou organização em sistemas de informação e como conhecimento, ou finalidade última. Daí à compreensão de Ingwersen (1992), da informação como algo que, perceptível, afeta e muda o estado de conhecimento do receptor, há uma valorização do sentido, ou do significado que ela adquire para a pessoa, em lugar e tempo determinados, pelo que o autor conclui que a primeira característica que o estudo da informação deve considerar é a relação entre o conhecimento e sua representação. 
O conceito de documento é analisado pelo seu valor expressivo e cognitivo (p. 45), em sua faceta significante. Denominado por Buckland (1991 apud MOREIRO, 2005, p. 45) “informação-como-objeto”, o documento é a possibilidade de a informação tornar-se tangível, graças à faculdade semiótica humana para a construção de signos. Completa-se com ele um ciclo em que os sujeitos, cada um contribuindo conforme suas capacidades e habilitações autor, documentalista, analista e receptor - produz, reconhece, traduz, identifica, valoriza, recupera e analisa a informação registrada, a partir de seus esquemas cognitivos organizadores.

O ciclo é facilitado significativamente com a intervenção da tecnologia nos processos informativos (p. 48), uma vez que "informar-se é uma combinação de esforço mental e processamento tecnológico”(MOREIRO, 2005, p. 48). Evoluindo desde os primeiros sucessos representados pela escrita e a imprensa, as tecnologias e canais empregados para representar materialmente as informações são consideradas por Moreiro como significantes, incluindo-se entre eles os computadores e programas, fatores intervenientes na criação de novos tipos de documentos.

Assim, pode-se analisar o suporte digital em relação às variações introduzidas no conceito de documento (p. 51). Percebe-se que os suportes vêm perdendo a importância para os conteúdos que, fixados em documentos eletrônicos, apresentam propriedades como: a possibilidade de acesso irrestrito; a abertura do documento, sua facilidade de manejo e atualização; a recuperação interativa da informação e a possibilidade de entrelaçamento interno e externo dos documentos eletrônicos com outras informações fisicamente conectadas graças às suas estruturas lógicas hipertextuais.

\section{OS SISTEMAS DE ACESSO E RECUPERAÇÃO DA INFORMAÇÃO}

Se a finalidade dos documentos é comunicar a informação, o processo documental só se completa quando a mensagem for efetivamente disponibilizada e essa por sua vez só adquire significado pela comunicação interpessoal. Entretanto, Moreiro alerta para questões decorrentes, especialmente da progressiva e ilimitada quantidade de documentos; da redução da vida informativa média das mensagens; da dispersão de publicações sobre temas específicos em periódicos de assuntos diversos; do crescimento de documentos auto-editados, graças aos efeitos dos avanços tecnológicos sobre a produção científica individual; da tendência crescente à especialização; e, da ausência de centros de documentação em alguns setores especializados.

A superação dessas questões é facilitada não somente pela compreensão do contexto social, econômico e político e dos fatores cognitivos presentes no processo, mas principalmente pela atuação de sistemas de informação, ou como define o autor, da intervenção artificial que permite aos usuários aceder à informação.

Considerados fundamentos dos sistemas de acesso e recuperação da informação (p. 64), destacam-se a intenção de controle e acesso à informação e as tarefas de processamento, pelo que todo sistema implica uma organização, aplicações técnicas e política de desenvolvimento, com as funções principais de: adquirir ou produzir documentos; conservar, 
isto é, armazenar e custodiar os recursos; identificar e representar, trabalho indicial que remete a um documento ou parte em que se encontra a informação desejada e difundir, ou seja, facilitar o acesso físico aos recursos o mais próximo e rápido possível.

O propósito de esclarecer o ciclo documental passa pela seleção de autores como Gerard e Prints (1936), para os quais este ciclo acolhe em uma mão a produção, classificação e conservação dos documentos e, na outra, a elaboração, difusão e utilização dessa documentação. Embora revitalizado por Besterman (1937) e Taube (1952), o conceito de ciclo documental foi retomado em 1978 por Vickery, que procura explicar os princípios teóricos da prática documental, diferenciando-os daqueles da Biblioteconomia, mas dando especial ênfase às leis de Ranganathan (1931).

Os princípios analisados inspiram pressupostos tais como o de que a suporte diferenciado corresponde diferente tipo de sistema (p. 68), ou seja, a materialidade e tipologia dos documentos impõem características práticas diferenciadas aos sistemas de informação. Esses aspectos definem-se a partir da proveniência ou origem dos documentos, da forma e da originalidade. Além disso, categorizam-se os sistemas segundo diversos critérios, os quais, combinados, geram possibilidades múltiplas de modelos. Independentemente de sua natureza e propósito, influenciados pelo clima de mudanças constantes da sociedade, da economia, da política e da tecnologia, tais sistemas deparam-se com a necessidade de ampliar suas responsabilidades e seu horizonte.

Assim ocorre com a biblioteca e o acesso digitalizado à informação (p. 73), cujos fundos tradicionalmente agrupam-se segundo princípios de classificações como a de Dewey e a Decimal Universal. Atualmente, diante do modelo de funcionamento em ambiente de rede de informação e recursos digitais, esses fundos deparam-se com funções mais precisas no sentido de difundir a informação, obter respostas pragmáticas e imediatas, colaborar com o sistema educacional, custodiar acervos, apoiar o desenvolvimento de atividades sociais e contribuir para as práticas e o desenvolvimento de pesquisas científicas. Assim, a biblioteca ultrapassa os limites impostos pelos seus muros físicos graças ao aproveitamento das tecnologias avançadas, demonstrando a inutilidade das tentativas de defini-la a partir dos suportes que administra uma vez que, desde os tabletes de argila até os discos digitais, passando por papiros, pergaminhos, todos os tipos de impressos, celulóide, fitas magnéticas e discos em suas diversas modalidades, essa instituição não desprezou nenhum como objeto de atenção, produção e tratamento (MOREIRO, 2005, p. 77). Sem esquecer as funções tradicionais, a biblioteca se torna híbrida, pois mantém suas coleções convencionais, tem acesso a suportes diversos por meios eletrônicos e gestiona coleções de documentos eletrônicos que não se limitam aos textos. Quanto às bibliotecas digitais, suas vantagens na forma de armazenagem, na facilidade de recuperação, nas novas estruturas de documentos que favorecem a interação e autonomia, apresentam como contraponto a permissão de espaços controversos do ponto de vista estético, ético e político.

Apontando o impacto da digitalização nos arquivos (p. 87), o autor os conceitua como veículos constantes para que as organizações, consideradas como sistemas, promovam a relação entre seus componentes internos e o intercâmbio cognoscitivo, entre elas e o exterior. Ao analisar a aplicação da informática e das telecomunicações na automatização total ou parcial de operações com documentos de arquivo, refere-se aos metadados e seu potencial nos 
processos de criação e utilização dos documentos informáticos, abrangendo os contextos administrativo de criação e tecnológico, sem deixar de referenciar a aceitação das normas International Standard Archival Description (ISAD) e International Standard Archival Authority (ISAAR).

O acompanhamento das tendências relativas aos sistemas de gestão da informação (p. 96) em diferentes organizações revela que: (1) a informação é um recurso que demanda administração adequada; (2) se a informação é um recurso com gestão própria, alguém na organização deve se responsabilizar por essa ação; (3) a gestão da informação não está exclusivamente relacionada com documentos, mensagens e dados, mas com todo o aparato de tratamento da informação. Assim, com ela estão relacionados os departamento de pesquisa e desenvolvimento, de engenharia, de operações, de marketing, de qualidade e de pessoal.

Entre os avanços relativos à gestão integrada da informação empresarial destacam-se os Data Warehouse, modelos organizadores de informações em organizações complexas, cujos méritos enquanto depósitos que abarcam informações externas e internas à empresa, redundam em menor custo para a tomada de decisões, maior flexibilidade na análise do contexto, melhor serviço ao cliente, idéias renovadoras para o redesenho de processos e alinhamento com os objetivos de rightsizing. Esses sistemas de armazenamento e gestão têm utilizado modelos de meta informação.

O museu, reconhecido como elemento de conhecimento e pesquisa (p. 102), especialmente graças aos trabalhos teóricos e práticos do Information Retrieval Group of the Museums Association (IRGMM) e do Museum Documentation Advisory Unit (MDAU), é principalmente um centro que, além de conservar, destina-se a informar. À missão de expor seus objetos, o museu agregou a de proporcionar condições ao trabalho, educação e pesquisa, resumidas em três objetivos: apoiar o estudo científico comparativo; atuar como escola difusora que utiliza todos os meios informativos existentes para educar seus visitantes e servir de depósito para as peças de interesse (MOREIRO, 2005, p. 103). Ao conceber a intermediação documental como uma obrigação científica dos museus, o autor enfatiza a necessidade de sistemas adequados de gestão e integração dos mesmos.

Os mesmos pressupostos se aplicam aos centros e serviços de documentação (p. 108), cujas práticas de intermediação voltam-se especialmente aos processos de busca e difusão de informações, ações típicas de uma organização que seleciona, adquire, armazena e recupera documentos específicos em resposta a demandas concretas, difunde, resume e indexa documentos e responde a solicitações difundindo documentos por sua referência ou conteúdo.

Com vistas à integração de funções e técnicas, o sistema global de informação (p. 112) é apresentado pelo autor para finalizar o capítulo dedicado aos sistemas de acesso e recuperação da informação. Infere-se que a ciência da informação ampliou notavelmente suas possibilidades, o que veio a influenciar as estruturas informacionais, os serviços e produtos e, conseqüentemente, não apenas o papel dos profissionais, mas também dos usuários da informação que manejam diretamente os sistemas. 


\section{EVOLUÇÃO HISTÓRICA DO ACESSO E CONTROLE DA INFORMAÇÃO DOCUMENTAL}

Um exercício diacrônico pela história e teoria da área compõe o quarto capítulo da obra. Relaciona-se à evolução do acesso e controle à informação documental, desde suas origens e descrevendo o que representaram os repertórios para o mundo antigo e medieval, a produção mecânica de impressos, a necessidade de bibliografias, o percurso do livro ao documento e da bibliografia à documentação. O processo de sistematização teórica e implantação metodológica da documentação (p. 155) inicia com as aportações de LaFontaine e Otlet (1908) para a organização do mundo documental na Europa. O Traité de Documentation, de Paul Otlet (1996), é um livro e referência para quem trabalha com sistemas de informação e foi a primeira obra a organizar a documentação como disciplina. Já, nos Estados Unidos, Dewey (1979) viria a contribuir para o amadurecimento do profissional bibliotecário.

Os organismos documentais (p. 170), como a International Federation for Documentation (FID), a International Federation of Library Association (IFLA) entre outros de caráter internacional e nacional, viriam a contribuir para a teoria e a prática da documentação em bases científicas. Surge desse modo uma nova proposta conceitual e aplicativa, a Ciência da Informação, com novos termos, novos conceitos e novos métodos. Esse corpo teórico que contribuiu para a identificação de funções sociais, métodos e técnicas concretos de trabalho, acompanhados da normalização internacional, favoreceu as primeiras tentativas de recuperação automática: a microfotografia e o aparecimento do American Documentation Institute (ADI). Assim, consolida-se a Ciência da Informação tendo como principais contribuições à visão premonitora de Vannevar Bush, a conferência da Royal Society Scientific Information, as fichas perfuradas e sua utilização científica e industrial, a obra coletiva Bibliographic Organization, a indexação coordenada mediante unitermos, a importância técnica da obra Information Storage and Retrieval, a International Conference on Scientific Information, o Informe Weinberg, fomento governamental da Ciência da Informação, o computador como tecnologia básica da informação, a informação como negócio, a utilização de métodos lingüísticos para o tratamento da informação e de modelos estatísticos ou probabilísticos para a análise do conteúdo. Destacam-se ainda os métodos de agrupamento e classificação e os métodos estatísticos de agrupamento em classes. Os modelos analíticos de caráter lingüístico, por sua vez, integram diferentes componentes, conforme os níveis em que atuam: morfológico-léxico; sintático; semântico e pragmático.

Esses fatores impulsionam as pesquisas na área de Ciência da Informação na direção de um processamento inteligente (p. 210), marcado por programas cada vez mais modulares e híbridos, a requerer para sua efetivação equipes multidisciplinares.

Delineiam-se os traços distintivos da Sociedade da Informação, a partir das origens da Internet (p. 212), da passagem da recuperação textual à recuperação multimídia, do impulso proporcionado pelos computadores à impressão eletrônica, das possibilidades da edição eletrônica e do fomento do setor audiovisual.

As conexões intertextuais, emulações da memória humana, permitem a mobilidade de construção e busca de informações, enquanto as revistas científicas de difusão digital ampliam 
as possibilidades de autor, editor e leitor, alinhando-se, com outros fatores, a um processo de provisão integrada de conhecimento científico.

\section{OS TERMOS E OS CONCEITOS}

No quinto e último capítulo, são destacados os conceitos básicos da área, assim como a terminologia que os define, fechando-se o caminho epistemológico do autor. Consciente das contradições que os termos documentação e ciência da informação apresentam, o autor recupera a construção histórica dos termos Bibliografia, Biblioteconomia, Documentação e Ciência da Informação, nessa ordem, para representar a atividade orientada pela existência da informação, caracterizada pela pertinência, economia de tempo e de dedicação, premissas para a transferência do conhecimento.

Ao isolamento de conceitos entre Bibliografia, que passa a ser disciplina autônoma, distinguindo-se da Paleografia e da Diplomática, e a Biblioteconomia, seguem-se questionamentos sobre a natureza desta última: reconhecê-la como saber científico ou conhecimento prático. Nessa retrospectiva, também se destaca a designação e alcance do termo Documentação, cujo conceito relaciona-se com o de Biblioteconomia, mas que está vinculado ao afã enciclopédico e globalizante.

Como resposta à necessidade de uma disciplina científica que estudasse as características da produção, fluxo e uso da informação, a Ciência da Informação desponta dentro do grupo das ciências sociais, tendo como singularidade sua composição interdisciplinar. Destacam-na Machlup e Mansfield (1983 apud MOREIRO, 2005, p. 287), em típica resenha coletiva de cinqüenta e seis trabalhos sobre o tema, produzidos por trinta e seis autores. Oferecem uma visão histórica dessa interpretação interdisciplinar, indicando os conceitos: ciências do conhecimento (conhecimento científico); informática; inteligência artificial; lingüística; biblioteconomia e ciência da informação; teoria da informação; cibernética e teoria de sistema e ciências sociais.

O aspecto interdisciplinar da ciência da informação afeta necessariamente a formação de seus profissionais, cuja valorização levará em conta: as habilidades tecnológicas e a gestão de redes de comunicação; a atenção preferencial ao cliente, o armazenamento, gestão e recuperação dos distintos suportes de informação e o desenvolvimento empresarial.

Além de apresentar as propostas conceituais soviética e alemã para fundamentar a ciência da informação, o autor fecha a obra analisando o conceito de Ciência da Informação, uma ciência de amplo espectro, com progressiva presença da tecnologia, especialmente quando se aplica aos sistemas de documentação e informação.

\section{CONSIDERAÇÕES FINAIS}

Resulta em obra densa, tanto dos pontos de vista histórico e teórico, quanto didático, especialmente pelo modo como foram desenvolvidos temas pontuais. Fornece-nos um panorama muito bem referenciado da área, com informações e sugestões de leitura para maior 
aprofundamento sobre os termos, conceitos, evolução e situação atual da informação documentária. Nesse sentido, a obra é valiosa para estudantes e pesquisadores, fornecendolhes reflexões e considerações capazes de revelar as características fundamentais para a compreensão do contexto teórico e prático dos saberes disciplinares e atividades profissionais voltadas à informação e, de modo muito especial, ao domínio científico da Ciência da Informação. Visualiza-se desse modo, o contexto teórico dos conhecimentos relativos ao campo e ao objeto de estudo da ciência da informação. Desde a compreensão sobre traços, componentes e processos próprios dos sistemas de informação e sua utilidade, passando por um exercício histórico da área e os fatores sociais, políticos e econômicos que compõem o seu contexto, destacam-se os conceitos básicos da especialidade, o papel da terminologia e o caminho evolutivo que nos é permitido acompanhar, como leitores privilegiados.

\section{REFERÊNCIAS}

BELKIN, J. Information concepts for Information Science. Journal of Documentation, v. 34, n. 1, p. 55-85, 1979.

BELZER, J. On foundations of Information Science. In: ASIS Annual Meeting. Information: Science and policies, 1979. Proceedings... White Plains: Knowledge Ind. Pub., 1979, p. 319325.

BESTERMAN. IID Comunication, 4, n.3, 1937

BRINER, L. A mathematical theory of indexing. In: ASIS Annual Meeting: The information age in perspective, 15, 1978. Proceedings... p. 55-58, 1978.

BUCKLAND, M. Information and information systems. Westport: Greenwood Publishing Group, 1991.

CASTELLS, M. La era de la información: economia, sociedad y cultura. Madrid: Alianza, 2001.

CEBRIÁN, J. L. Algunas certezas sobre la sociedad digital. In: CARIDAD SEBASTIÁN, M. (coord.) La sociedad de la información: política, tecnologia e industria de los contenidos. Madrid: CEURA, 1999.

DEWEY, M. Decimal classification and relative index. 19 ed. New York: Forest Press, 1979.

DRUCKER, P. F. Post-capitalist society. New York: Butterworth-Heinemenn, 1993. 
FOGL, Jiri. Transformation of information. Ceskolovenska Informatika, v. 21, n. 7/8, p. 196-201, 1979.

GARFIELD, E. Information theory and other quantitative factors in code design for document card systems. Journal of Chemical Documentation, v. 1, p. 70-75, 1961.

GÉRARD, J.; PRINS, J. A. Introduction a l'étude et à la methode de documentation. Paris: Institut International de Coopération Intellectuelle, 1936.

INGWERSEN, P. A. Information and Information Science in context. Libri, v. 42, n. 2, p. 95, 1992.

LA FONTAINE, H; OTLET, P. L'Etat actuel des questions bibliographiques et l'organisation internationale de la Documentation. IIB Bulletin, 13, 1908.

MACHLUP, H.; MANSFIELD, J. The study of information interdisciplinary messages. New York: Wiley, 1983.

MARINO, J. B. Quelques applications de la théorie mathématique de la communication em Sciences de l'information. Documentaliste, v. 20, n. 2, 1983.

McHALE, B. Postmodernist fiction. New York: London: Methuen, 1987. V. t. McHALE, B. Constructing postmodernism. London: Rutledge, 1992.

MOLES, A. Teoria estructural de la comunicación y sociedad. México: Trillas, 1983.

MOORE, N. The information society. In: World Information Report 1997-1998. Paris: UNESCO, 1999.

MOREIRO GONZÁLEZ, José Antonio. Conceptos introductorios al estudio de la información documental. Salvador: EDUFBA/Fondo Editorial de la Pontificia Universidad Católica del Perú, 2005.

OTLET, P. El tratado de documentación: el libro sobre el libro. Teoría y práctica. Traducción de Ma Dolores Ayuso. Murcia: Universidad de Murcia, 1996.

PÉREZ TORNERO, J. M. Los nuevos procesos de mediación: del texto al hipermedia, em comunicación y educación en la sociedad de la información. Barcelona: Paidós, 2000.

PORAT, M. The information economy: definition and measurement. Washington: US Government Office, 1977.

RANGANATHAN, S. R. Five laws of Library Science. London: Blunt, 1931. 
SCHREIDER, J. A. Informatsiia i metainformatsiia. Nauchno-Technicheskaia Informatsiia. Serie 2, n. 4, p. 3-10, 1974.

SCHULTZ, C. K. H. P. Luhn: pioneer of Information Science: selected works. New York: Spartan Books, 1968.

SHANNON, C. E.; WEAVER, W. The mathematical theory of Communication. Urbana: University of Illinois Press, 1949.

SHANNON, C. Prediction and entropy of printed english. Bell System Technical Journal, v. 30, n. 1, p. 50-64, 1951.

SHERA, J. H. Documentation in action. New York: Reinhold 1956.

TAUBE, M. Special Librarianship and Documentation. American Documentation, 3, 1952.

VICKERY, A. Information Science in theory and practice. London: Butterworths, 1978. 